Proceeding Paper

\title{
A Review of a Teaching-Learning Strategy Change to Strengthen Geomatic Concepts and Tools in the Biosystems Engineering Academic Studies at the Universidad de Costa Rica ${ }^{\dagger}$
}

\author{
José Aguilar* $*$ and Matías Cháves
}

\author{
Escuela de Ingeniería de Biosistemas, Universidad de Costa Rica, San Jose 11501-2060, Costa Rica; \\ matias.chaves@ucr.ac.cr \\ * Correspondence: jose.aguilar@ucr.ac.cr \\ + Presented at the 13th EFITA International Conference, online, 25-26 May 2021.
}

check for updates

Citation: Aguilar, J.; Cháves, M. A Review of a Teaching-Learning Strategy Change to Strengthen Geomatic Concepts and Tools in the Biosystems Engineering Academic Studies at the Universidad de Costa Rica. Eng. Proc. 2021, 9, 44. https:// doi.org/10.3390/engproc2021009044 Academic Editors: Dimitrios Aidonis and Aristotelis Christos Tagarakis

Published: 25 January 2022

Publisher's Note: MDPI stays neutral with regard to jurisdictional claims in published maps and institutional affiliations.

Copyright: (C) 2022 by the authors. Licensee MDPI, Basel, Switzerland. This article is an open access article distributed under the terms and conditions of the Creative Commons Attribution (CC BY) license (https:// creativecommons.org/licenses/by/ $4.0 /)$.

\begin{abstract}
A different teaching-learning strategy was implemented in the geomatic applications in the Biosystems Engineering course. The strategy, which was based on the educational theory of constructivism, promoted the strengthening of geomatic concepts and tools through case studies that aim to balance lectures and practices to achieve an efficient teaching-learning level. The evaluation and follow-up of this case study review the project's progress and include students' opinions, as collected in a survey over multiple semesters. The strategy allowed the classroom to become a space that promoted the benefit of the student's experience in their professional training.
\end{abstract}

Keywords: case studies; geoscience; geomatic; curricular design; constructivism; software engineering

\section{Introduction}

As a public higher education institution, the Universidad de Costa Rica (UCR) is committed to improving teaching, research, and social action. Academics and students use humanistic values to seek sustainable solutions to national problems in a global context. Career preparations related to agriculture and natural resources need transformation for higher learning goals in modern times. In 2013, the UCR Agricultural Engineering career changed to Biosystem Engineering, aligning with the digital revolution incorporating new subjects such as information and communication technologies (ICT). Viewed as a key and transversal part of the academic program, one of the areas of modernization was the informatics class in agriculture, which was renamed Geomatic. Geomatic is an essential subject in the biosystems program that aims to solve society's complex problems in a challenging way. Teachers also needed to change their way of teaching. One change made was balancing lectures and practices to achieve an efficient teaching-learning level. Students wanted to address social problems in their learning experience. Jean Piaget [1] developed the theory of constructivism and hypothesized that "humans create knowledge through the interaction between their experiences and ideas". With this approach, teacher and student develop a much closer learning strategy connected to life experiences, assuring that the knowledge is learned well. Holley [2] presented an example of the methodology success where she found there is a significant increase in positive attitudes toward the subject, and the results from tests demonstrated a significant improvement. Holley indicates that "the comparison of pretest and posttest shows a significant change" and that it helped the students in their learning and especially in their confidence. A case study methodology can be an effective way for the teacher who wants to improve the learning experience by developing higher cognitive skills in the students. However, this requires a much longer dedication to class preparations to have an effective methodology [3]. In an engineering career, where the context with the real world is fundamental, every engineering course 
should have as many exposures to the world as possible. More specifically, adding agriculture to the engineering-based career and combining it with ICT produces a much more positive impact on the student [4]. Other authors believe that the modernization of the learning processes and development of information processing competencies and cognitive skills in students through ITC enables greater efficiency in the institutional and academic management processes of schools [5].

\section{Materials and Methods}

One of the teacher's roles is to design case studies based on actual problems that need potential solutions to promote two learning abilities. The first ability is using the appropriate knowledge and skills to identify, formulate, research (literature), and analyze engineering problems with geomatic solutions. This results in significant conclusions, using engineering principles. The second ability is applying the knowledge and fundamentals of geomatics tools to add to the space-time phenomena to engineering solutions. Case studies create learning in spaces that generate knowledge with a methodological logic of background, where the following possibilities are considered:

1. Problem planning, design, and execution of solutions;

2. Transformation of content into procedural, attitudinal, or conceptual tools;

3. Strengthened relations between teachers, students, and agricultural producers; and

4. Ability to work cooperatively to build knowledge among work teams.

\section{Results}

\subsection{Case Study Portfolio Design}

Both the biosystems engineering career and geomatic have broad and diverse concentrations. ICT applications are the critical link between the two. The ability to articulate them requires an adaptive and gradual teaching design. The case study methodology facilitates a real problem using an appropriate subset of both areas (Figure 1a). The case study portfolio design considers problems where temporal and spatial variability is necessary for decision making. Government, society, and academia are essential to strengthen the timeliness conception. The resulting cooperation promotes public and private articulations for their involvement and definition. The coordination required between the distinct groups is broad and requires effective communication, collaboration, and committed cooperation. It is essential to show the benefits of the parties by achieving win-win scenarios. The design and definition of the case studies were established from a national project for the digital transformation of agriculture, called Agroinnovación 4.0, established by the Ministry of Agriculture and Livestock. This project included both the private and public sectors, where the potential of geomatics tools for decision-making processes through models were discussed. A preliminary list of cases was established from these meetings. The case studies were prioritized according to importance and data set availability. The terms of reference were established with the facilitators of the government, producers, and academia sectors.

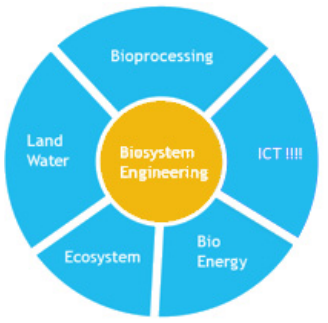

(a)

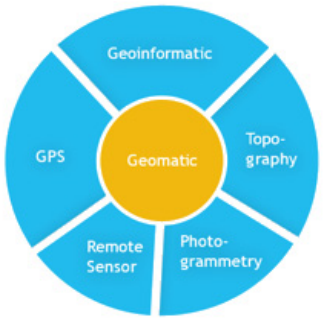

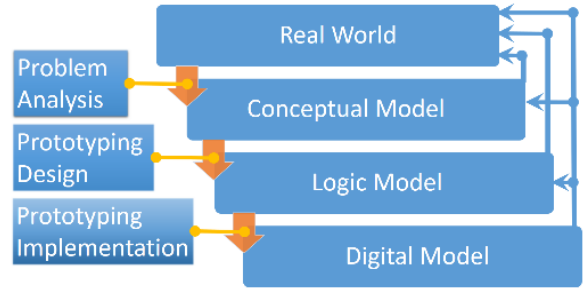

(b)

Figure 1. (a) Both the biosystems engineering career and geomatics have broad and diverse concentrations linked by ICT; (b) process flow diagram used to build the prototype and follow-up of the case studies. 


\subsubsection{The Evaluation and Follow-Up of the Case Studies}

Each project's progress has a scope delimitation according to the terms of reference with the help of the facilitators. The final project integrates the three processes with feedback and maturity of the prototype reached. Figure $1 \mathrm{~b}$ shows the process flow diagram used to build the prototype. It starts with analyzing a real-world problem with its challenges and the decision-making models required to specify a conceptual model. The prototyping design implies an investigation accompanied by expert criteria to define the necessary datasets, the design of the geographic database, and the development of a cartographic model that enables the definition of the logic model. Finally, the prototyping implementation is based on its digital model.

The problem analysis allows students to have a practical approach to problems by counting the perspectives of the farmers, the Ministry of Agriculture and Livestock official facilitator, and academia. The background and considerations of the case study allow the conceptual model to be set up through systematization tools such as concept maps, process flow diagrams, and the quality evaluation of temporal and spatial databases. The definition of the decision scale and delimitation are fundamental in this process. Prototyping design implies a review of the state of application in a Costa Rican context. Expert criteria are relevant and investigated to define the data set, organization, the model to be used, and the validation criteria according to the work scale. The prototype implementation seeks to specify the outputs of the proposed model based on the progress project. Finally, the students share the preliminary results with the target groups to gain their feedback and use it for the calibration and criteria validation processes. Once settings and validation considerations are in place, the students share their final experiences with colleagues and facilitators.

\subsubsection{General Perception of Students}

Figure 2 shows the students' responses on how their interest was before receiving the course and after it. The highest values are in the category that initially had interest and increased it at the end of the course. It is essential to highlight the first semester of 2020; the values of interest remain high despite the COVID-19 pandemic effect. Table 1 shows the student's perception responses related to learning method aspects of the balance of theory and practice, critical thinking, examples of the country's reality, research, and ethics. Whereby graphing these elements, as seen in Figure 2, the values are high. At the end of the course, the students' general opinions indicate that the teaching approach has an approval above $80 \%$ over four different semesters.

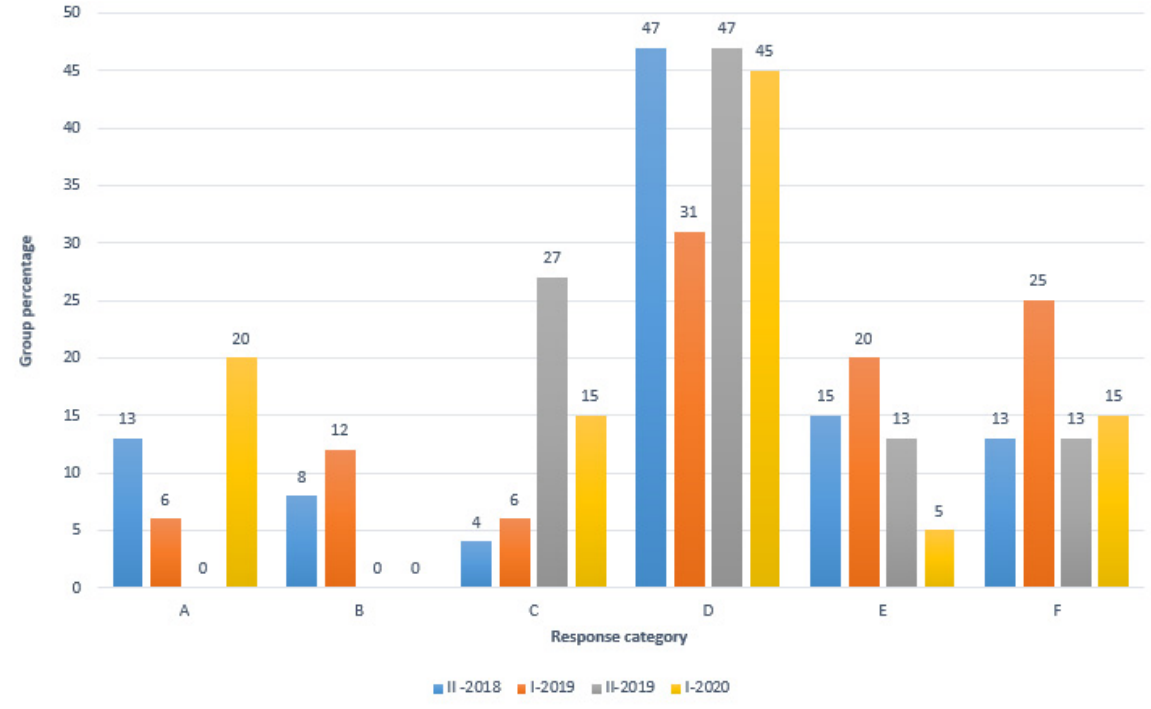

Figure 2. A: At first, I had interest and lost it; B: At first, I had no interest and still do not have it: C: At first, I had no interest, and now I do; D: At first, I had interest and kept it; E: At first, I had interest and increased it; F: Teacher has no influence. 
Table 1. Students' perception responses related to learning method.

\begin{tabular}{ccccc}
\hline The Learning Method Provides & II-2018 (\%) & I-2019 (\%) & II-2019 (\%) & I-2020 (\%) \\
\hline A balance between theory and practice & 72 & 74 & 93 & 93 \\
Activities that allow students to think in a & 70 & 83 & 90 & 90 \\
diverse and innovative critical way & 94 & 97 & 96 & 97 \\
Examples related to future profession & 93 & 94 & 97 & 97 \\
Discussions with the reality of the country & - & 95 & 97 & 97 \\
Activities involving research & 91 & & 95 \\
Topics of ethics, values, and responsibility & &
\end{tabular}

\section{Discussion}

The top value from the proposed teaching-learning strategy is encouraging collaborative work between students detecting deficiencies in the group and promoting teamwork. To support leadership attitudes, students identify how they can work to benefit all, helping the group analysis. The case study strategy allows the student to develop knowledge and skills, while the teacher provides strategical guidance by the facilitators. Values from the students' experience also accompany the proposed solutions from the theory and practical support. Accordingly, geomatic concepts and their tools applied in the Biosystems Engineering career are more effective if the connection with the real-world case studies is relevant. It is important to highlight that problem analysis and research abilities are fundamental for solutions, creativity, negotiation, teamwork, leadership, attitudes, and skills. Case studies allow the classroom to become a space that promotes the benefit of the students' life experiences in their professional training. The success factor in achieving the learning goals rely on the progress project that encourages and facilitates the gradual and adaptive follow-up from the theory and practice of geomatics.

Author Contributions: Conceptualization, J.A.; methodology, J.A.; validation, J.A. and M.C.; formal analysis, J.A. and M.C.; investigation, J.A. and M.C.; resources, J.A. and M.C.; writing-original draft preparation, J.A.; writing-review and editing, J.A.; visualization, J.A.; supervision, J.A.; project administration, J.A. All authors have read and agreed to the published version of the manuscript.

Funding: This research received no external funding.

Institutional Review Board Statement: Not applicable.

Informed Consent Statement: Not applicable.

Acknowledgments: We are grateful to Ing. Jairo González from MAG and lead of Agroinnovación 4.0 for his support given in the portfolio cases studies and Ing. Alvaro Brenes and Ing. Fernando Vázquez, professors of Facultad de Ciencias Agroalimentarias, as the facilitators in the case studies, and especially the farmer involved. We also thank all the students from the course Geomática aplicada en Ingeniería de Biosistemas IB-0011 and IB-0050 at UCR. Finally, we thank Luke Reese from MSU for his writing review.

Conflicts of Interest: The authors declare no conflict of interest.

\section{References}

1. Bru, B. Constructivism. In Education Research: Across Multiple Paradigms; Kimmons, R., Ed.; EdTech Books, 2021. Available online: https:/ / edtechbooks.org/education_research/constructivismy (accessed on 1 May 2021).

2. Holley, E.A. Engaging engineering students in geoscience through case studies and active learning. J. Geosci. Educ. 2017, 65, 240-249. [CrossRef]

3. Yadav, A.; Beckerman, J.L. Implementing case studies in a plant pathology course: Impact on student learning and engagement. J. Nat. Resour. Life Sci. Educ. 2009, 38, 50-55. [CrossRef]

4. Sankar, C.S.; Varma, V.; Raju, P.K. Use of case studies in engineering education: Assessment of changes in cognitive skills. J. Prof. Issues Eng. Educ. Pract. 2008, 134, 287-296. [CrossRef]

5. Lindsey, A.J. Professional development participation by teachers facilitated student exposure to agriculture. Nat. Sci. Educ. 2020, 49, e20034. [CrossRef] 